\title{
Caloric Restriction and Antiaging Effects
}

\author{
Lan Xiang Guoqing He \\ School of Biosystems Engineering and Food Science, Zhejiang University, Hangzhou, China
}

\section{Key Words}

Caloric restriction · Aging • Lifespan · Energy metabolism

\begin{abstract}
Caloric restriction (CR) is widely used to study aging processes. It is a simple and highly reproducible method for delaying the aging process, preventing the onset of aging-related diseases and extending average or maximum lifespan. However, the mechanism underlying these effects of $C R$ is still not clear. CR can inhibit growth, reduce body size and maintain a low body temperature. At the same time, there is a measurable decrease in the volume of adipose tissue, hyperglycemia and hyperinsulinemia, accompanied by modifications of lipid and energy metabolism and increased resistance to endogenous and extraneous stress. The metabolic changes induced by dietary restriction, the inhibition of fat deposition in nonadipose tissue and the effects on signal transduction are considered the most likely candidates for mechanisms underlying the effects of CR.

Copyright ๑ 2011 S. Karger AG, Basel
\end{abstract}

\section{Introduction}

In 1935, McCay et al. [1] first reported that caloric restriction (CR) could extend the lifespan of ablactated rats. During the following 70 years of research, CR was also termed dietary restriction, food restriction and energy restriction. Applying CR to mammals is designed to induce undernutrition without malnutrition, with food in- take reduced by usually $30-40 \%$ compared to ad libitum (AL) levels. It is a simple method for inducing a highly reproducible extension of lifespan that has been widely used in research on aging [1].

$\mathrm{CR}$ extends the average and maximum lifespan and delays the onset of age-associated alterations in diverse species $[2,3]$. Lifespan extension by CR has been observed in a number of organisms ranging from yeast, Caenorhabditis elegans and Drosophila melanogaster to rats $[4,5]$. CR is thought to exert antiaging effects including an increased resistance to endogenous stresses such as hyperglycemia and hyperinsulinemia, to changes in energy metabolism and oxidative stress, or to extraneous environmental stresses. However, a detailed mechanism for CR responses has not yet been established.

In 1989, Holliday [6] introduced the compatibility hypothesis as an explanatory mechanism for the antiaging and lifespan extension effects of CR. The importance of neuroendocrine and metabolic changes effected by food insufficiency was explained from an evolutionary viewpoint. In periods when abundant food is available, body size would grow quickly and reproduction would be vigorous. Excess energy would be converted into fat and stored as adipose tissue. In subsequent periods of food shortage, body growth and reproduction would be inhibited and the energy stored in adipose tissue used to extend the lifespan until the diet again became sufficient. The animals that had this ability to adapt to an insufficient diet were therefore selected during the course of evolution. CR could extend the lifespan through reactions occurring in response to insufficient diet. Therefore, in this

\section{KARGER}

Fax +4161306 1234

E-Mail karger@karger.ch

www.karger.com
(C) 2011 S. Karger AG, Basel

0250-6807/11/0581-0042\$38.00/0

Accessible online at:

www.karger.com/anm
Guoqing $\mathrm{He}$

Department of Food Science and Nutrition

School of Biosystems Engineering and Food Science, Zhejiang University

Hangzhou 310029 (China)

Tel./Fax +86 5718697 1166, E-Mail gqhe@zju.edu.cn 
review, we have generalized CR to include metabolism, responses of the neuroendocrine system, signal transduction changes and molecular mechanisms of antiaging.

\section{Effects of CR on Metabolic Changes}

CR is different from starvation. The levels of plasma leptin, insulin, growth hormone $(\mathrm{GH})$ and luteinizing hormone (LH) were shown to be low, while corticosterone was very high in CR and fasting groups $[7,8]$. However, the respiratory quotient (RQ) is low and the source of energy shifts from glucose to lipids in starvation. Fats from white adipose tissue are channeled into mitochondrial $\beta$-oxidation to provide ketones as a fuel source for the brain $[9,10]$. Fasting can ultimately activate the transcription factor of peroxisome proliferator-activated receptor- $\alpha$ (PPAR- $\alpha$ ), which induces expression of many genes related to mitochondrial $\beta$-oxidation, peroxisome $\beta$-oxidation and microsome $\omega$-oxidation. The activity of oxidative processes could protect against fatty liver [11, 12].

In turn, in a CR rat group, the RQ was high after food intake, but was low before food intake. Daily food intake brought about large changes in RQ, whereas the daily RQ changes seen in AL rats were relatively small [13]. The AL rats could simultaneously utilize glucose and fats as energy sources according to a fixed ratio. However, the CR rats mainly utilized glucose after food intake and essentially used fat metabolism before food intake due to exhaustion of glycogen stores. The CR rats reduced the fuel for mitochondrial $\beta$-oxidation before food intake. PPAR$\alpha$ and gene expression related to mitochondrial $\beta$-oxidation were increased. Free fatty acids and ketone bodies in blood were higher prior to feeding than after food intake. In contrast, the total fats, triglycerides, total cholesterol and free cholesterol, phospholipids and free fatty acids were decreased in the CR rats after food intake [13]. However, the gene expression of ADD1/SREBP1, the synthesis of fatty acids and the activity of acyl-coenzyme A carboxylase in liver were significantly increased. Furthermore, $\mathrm{CR}$ activated the gene expression related to glucose, amino acid, lipid and energy metabolism without an effect of food intake [14].

Consequently, CR rats with a low RQ before food intake utilized endogenous fatty acids from white adipose tissue for basic mitochondrial $\beta$-oxidation to produce ketones. In contrast, CR rats with a higher RQ primarily used sugar from food as fuel, with surplus fuel used to synthesize fatty acids in the liver, which were then stored in white adipose tissue as triglycerides. The end result is that CR can induce fatty acid synthesis in the liver and activate mitochondrial $\beta$-oxidation through PPAR- $\alpha$. Lastly, CR improves the efficiency of lipid metabolism and inhibits lipid deposition in nonadipose tissue [14].

\section{Effects of CR on the Neuroendocrine System}

The gonadal, thyroid and GH-insulin-like growth factor 1 (GH-IGF-1) axis is suppressed by long-term CR. However, CR activates the adrenal glucocorticoid system. CR upregulates orexigenic peptide and neuropeptide $\mathrm{Y}$ while downregulating anorexigenic peptide and proopiomelanocortin [15-17]. The plasma IGF-1 level is significantly reduced in CR rats [18] and the plasma leptin concentration in $\mathrm{CR}$ rats is also lower than that in $\mathrm{AL}$ rats [19]. The hormonal profiles are the same in CR and fasting animals. However, since fasting is a short-term intervention to modulate energy homeostasis, it is necessary to distinguish the short-term and the long-term signals in the hypothalamus that regulate energy expenditure.

\section{Effects of CR on Rodents}

\section{Small Body Size, Delay of Growth and Maturation, and Inhibition of Reproduction}

CR inhibits growth and body size after maturation and reduces body weight $[2,3]$. GH and hormones such as IGF are considered to play important roles in these responses. GH in the pituitary gland is reportedly secreted as a pulse in an AL-fed group, whereas this secretion pattern is not apparent in a CR group [20]. The IGF-1 level in blood is decreased by about $25 \%$ [18].

CR also inhibits sexual maturation of both males and females. The inhibition by CR is stronger for females than for males. A reduction in LH by CR maintains a low follicle-stimulating hormone (FSH) level and decreases the size of the sex organs while maintaining reproductive ability $[21,22]$. Restriction (50\%) in daily food intake for 20 days significantly reduced plasma prolactin and testosterone levels without affecting basal LH and FSH concentrations and testicular weight in male rats [23]. In females, CR maintains the estrous cycle during aging. A female group fed AL after a 7- or 8-month period of CR showed an increased frequency of estrous cycles and numbers of progeny compared with a control group without CR. CR does not delay the aging of sex organs in males [23]. The levels of LH and FSH in blood are differ- 
ent from those seen during starvation. Circulating $\mathrm{LH}$, thyroid-stimulating hormone, GH and prolactin were significantly depressed in acutely and chronically starved rats, and FSH was lowered only in acutely starved rats. After 7 days of refeeding, serum levels of $\mathrm{LH}$ and FSH were significantly higher than in AL-fed controls [24]. In addition, starvation markedly decreased plasma insulin and testosterone levels in male rats. The weight of the testes was maintained, whereas the testicular interstitial fluid volume decreased [25].

\section{Hypercorticosteronemia}

In mammalian species, the hypothalamic-adenohypophyseal-adrenal cortical glucocorticoid system takes part in successfully coping with stressors. CR enhances the daily peak levels of plasma free corticosterone in rats. The free corticosterone in a CR group was 2- to 8-fold higher than in an AL group [26]. Corticosterone as a stress hormone and CR provided light stress hormesis over a long period. This hormesis of light stress is considered to be the most important reason for the antiaging effects of and lifespan extension by CR [5].

\section{Modification of Hyperglycemia and Hyperinsulinemia}

$\mathrm{CR}$ reduces the glucose and insulin levels in the blood when the stomach is empty [27]. Glucose tests show that in CR rats, glucose disposal after glucose load is facilitated without any significant surge of serum insulin, and insulin tolerance tests also indicate an increase in insulin sensitivity. Similar effects are seen after glucose and insulin load in dwarf transgenic rats, in which the $\mathrm{GH}$ IGF-1 axis has been selectively suppressed by overexpression of antisense GH transgene. CR in these tg/- rats further facilitates glucose disposal during glucose and insulin tolerance tests [28]. These findings suggest that both shared and separate mechanisms exist for regulating the glucose-insulin system between CR and the reduced GH-IGF-1 axis.

\section{Reduction in Metabolic Rate and Hypothermia}

The importance of metabolic rate during the aging process has been apparent since ancient times. CR before food intake transiently decreases the unit lean body mass from birth to 6 weeks of rats, but this effect is lost after 12 weeks and large differences are not observed until 18 months $[29,30]$. Based on this, it is very difficult to consider that metabolic rate plays any important role in the antiaging effects of and lifespan extension by CR. On the other hand, CR induces low body temperature [31, 32], but this effect is lost when mice are fed at $30^{\circ} \mathrm{C}$. Moreover, calorie-restricted monkeys have lower body temperatures and insulin concentrations than do control monkeys [33], and both these variables are biomarkers for longevity in rodents. These findings suggest that low body temperature induced by $\mathrm{CR}$ might contribute to antiaging and extension of lifespan by CR.

\section{Reduction in Adipose Tissue and Phenotype Changes}

The reduction in body size and body weight by CR also decreases the volume of adipose tissue. CR strongly affects fat volume in internal organs more than body weight or adipose tissue levels $[29,34]$. Under normal conditions, with increased age, the volume of adipose tissue also is increased. CR inhibits this change in response to aging $[29,30,34]$ and significantly decreases the size of fat cells in adipose tissue [14]. Some evidence indicates that CR induces changes in gene expression related to metabolism of sugars, amino acids and fats, and to mitochondrial function. On the other hand, gene expression related to inflammation, blood vessel regeneration, extracellular matrix and the cytoskeleton-related genes are inhibited by CR [14]. These changes in gene expression are not affected by the pattern of food intake.

Some of these gene changes are also seen for experimental in vitro fat cell differentiation. There is a regressive correlation with gene expression in adipose tissue of obese animals [14]. Furthermore, the changes in metabolism are in part induced by gene expression of transcription factors that activate $\beta_{3}$-adrenergic receptors, reduce leptin and increase SREBP1/ADD1 gene expression [14].

The cytokines and hormones derived from adipose tissue are referred to as 'adipokines'. Leptin is an adipokine that can control food intake and energy consumption. Animals reportedly increase food intake and become obese when the leptin control mechanism is unbalanced [35]. Leptin levels in the blood are dependent on the volume of adipose tissue and can also be increased with increases in food intake [19]. CR significantly inhibits the expression of leptin mRNA [14]. The plasma leptin shows the same circadian change as seen for increased ingestion behavior. CR can reduce plasma leptin levels by $50 \%[19]$.

Adiponectin, another main adipokine, is derived from special small fatty cells and controls the energy balance and metabolism of glucose and fats [36]. Plasma adiponectin is reduced in patients with type 2 diabetes and obesity. It induces an increase in triglyceride deposition in skeletal muscle and liver [37,38]. Adiponectin activates 5'-AMP-activated protein kinase (AMPK) and inhibits synthesis of glucose in the liver. It may also take part in 
activities involving glucose utilization and fatty acid oxidation [39]. CR can increase the plasma adiponectin levels 2- or 3-fold [40]. Therefore, CR not only reduces the volume of adipose tissue but also strongly induces secretion patterns and gene expression patterns that change the nature of the fatty cell.

\section{Involvement of CR in Cell Damage and Antiaging}

Lower insulin sensitivity is related to obesity, but also to excessive triglyceride deposition in nonadipose tissue [41]. Furthermore, steatosis induces lipotoxicity or lipoapoptosis [42]. This lipotoxicity is apparent in the $\beta$-cell of pancreas, in cardiac muscle and in skeletal muscle in type 2 diabetes and in insulin tolerance. In addition, excessive triglycerides promote lipid peroxidation [41]. A contribution of reactions involving free radicals and hyperglycemia to aging has been proposed [43]. Steatosis of nonadipose tissue in the liver induces tumor necrosis factor- $\alpha$ and cytokine production in cytoskeleton and promotes inflammation [44]. However, CR inhibits inflammation processes by increasing activity of nuclear factor$\kappa \mathrm{B}$, tumor necrosis factor- $\alpha$ and inducible nitric oxide synthase [45]. At the same time, CR also differentially inhibits and lowers insulin sensitivity, lipotoxicity, free radicals and other reactions. Under normal conditions, leptin, adiponectin and activity of PPAR- $\alpha$ in nonadipose tissue play important roles in the inhibition of steatosis [46-48]. Furthermore, CR can reduce the triglyceride content in hepatocytes and affect hepatic insulin sensitivity and glucose production. In addition, short-term CR resulted in increases in insulin sensitivity, in both nondiabetic and type 2 diabetic subjects [49].

\section{Changes in Signal Transduction by CR}

Recent studies on long-lived mutants of lower organisms and rodents have also indicated that reduced insulin-like signaling or GH-cIGF-1 signaling can extend the lifespan of these animals [50]. Since CR diminishes $\mathrm{GH}$ IGF-1 signaling as serum insulin levels are lowered, it thereby acts on aging and lifespan in animals [51]. The energy-sensing AMPK is a candidate for mediating CR responses in prolonging lifespan. AMPK is activated in response to decreased energy or glucose levels, which are consequences of CR [52], and in specific cases is induced by CR itself [53]. FOXO factors are activated and decrease the activity of the insulin signaling pathway $[54,55]$. In
C. elegans, the FOXO transcription factor DAF-16 mediates longevity due to a mutation in the insulin receptor daf-2 $[56,57]$. Although the lifespan extension due to the eat-2 mutation and to several $\mathrm{CR}$ regimens has been shown to be independent of FOXO/DAF-16, FOXO might still mediate lifespan extension under other CR experimental conditions. FOXO/DAF-16 is a direct in vitro substrate of AMPK and AMPK increases FOXO-dependent transcription. Together, these results point to the AMPKFOXO module as a central pathway in the regulation of lifespan by CR.

\section{Molecular Mechanism of CR Antiaging Responses}

The molecular mechanisms underlying CR responses that extend the lifespan in many species remain unclear. Some specific signals such as IGF have been implicated in lifespan extension in lower organisms [58]. In the following, we discuss the antiaging effects of CR, focusing on the mechanism of sirtuins, target of rapamycin (TOR)/ AMPK and pha-4/SKN-1.

The sirtuin family is a critical regulator of lifespan. Both deletion and overexpression of sirtuins affect the lifespan of lower organisms [59]. Sirtuins are NAD+-dependent protein deacetylases and exert regulatory functions through deacetylation of a wide rage of protein targets. There are 5 sirtuins found in budding yeast [60], 4 sirtuins in C. elegans and 7 sirtuins in mammals [61]. After Sir2 of yeast as the first gene discovered in this family, much evidence indicated that Sir2 protein was involved in transcriptional silencing at cell-mating-type loci and telomeres in yeast, and suppressed recombination of yeast ribosomal DNA [62, 63]. Kaeberlein et al. [64] first indicated that extra copies of Sir2 extended lifespan by up to $30 \%$. Similar antiaging effects of Sir2 were subsequently observed in C. elegans and the fruit fly [4, 64-67]. Human sirtuins (SIRT1-7) share the catalytic domain with Sir2 [61]; SIRT1-3 and 5 show NAD+-dependent protein deacetylase activities, while SIRT4 and 6 have monoADP-ribosyl transferase activities. NAD+ required by sirtuins as a cosubstrate suggests that sirtuins might act as sensors of cellular energy and redox states. Sir2 in yeast and its mammalian homologue SIRT1 can be upregulated by CR [68].

The amino acid-sensing TOR is a conserved serine/ threonine protein kinase and regulates protein synthesis and growth in response to nutrient intake [69]. Recently, the TOR pathway has been suggested as another mechanism through which CR may act. TOR comprises a rapa- 
mycin-sensitive and an insensitive complex and both of them can regulate downstream targets [70, 71]. A reduction in amino acid intake extends lifespan in yeast [72], Drosophila [73] and rodents [74, 75]. Therefore, TOR signaling is thought of as the mechanism whereby altered nutritional intake could result in organism-wide changes in aging processes.

AMPK is another important potential mediator of effects of CR. It is a key sensor of cellular energy levels and regulates the TOR and insulin/insulin-like signaling pathways under low-nutrient conditions [76]. Under lowenergy conditions, AMPK inhibits energy-consuming processes through the inhibition of TOR signaling [77, 78]. Therefore, AMPK like TOR plays a role in aging and stress resistance.

To understand the molecular regulating mechanisms of longevity and survival in animals, many mechanismbased experiments were conducted. Recent reports identified two transcription factors, PHA- 4 and SKN-1, which could regulate the extension of lifespan by CR in C. elegans $[79,80]$. Pha- 4 was found to be the ortholog of the mammalian Foxa family of forkhead transcription factors (Foxa1, 2 and 3) in the worm [81]. It is bifunctional in early development and in maintaining metabolic homeostasis. The role for PHA-4 in CR-mediated longevity in C. elegans was revealed by an RNAi-based screen testing [82]. The pha- 4 gene produces three PHA-4 protein isoforms called PHA-4 A, B and C that differ only at their $\mathrm{N}$-termini [76]. Panowski et al. [80] indicated that PHA-4 affected lifespan independently of its developmental function. CR induces FoxA $[83,84]$ and PHA-4 expression. Therefore, like the Foxa family members, PHA-4 has a role in lifespan extension by CR and early development.

SKN-1 is the worm ortholog of nuclear factor-E2-related transcription factors Nrf1 and Nrf2 [85]. The Nrf proteins can induce expression of phase II detoxification enzymes in the liver and digestive tract in response to oxidative stress and xenobiotics [86-88]. During adulthood, SKN-1 involves resistance to damage induced by oxidative stress [89]. Therefore, SKN-1 could be a key regulator of the response to CR [76].

\section{Discussion and Conclusion}

In this paper, we focused on the effects of CR on metabolic changes, the neuroendocrine system, cell damage and aging to provide an overview and give the latest insights into molecular mechanisms of CR in antiaging effects in lower organisms and rodents. It can offer important information for interdisciplinary research on nutrition metabolism and antiaging. Further, this information can provide a background for the utilization of CR to delay the aging process in humans and as a therapy for aging-related diseases like Alzheimer's and Parkinson's disease. CR is widely used as a novel model for aging research. The latest research report indicated that dietary restriction can increase longevity in humans $[89,90]$. CR changes the endocrine and neuroendocrine systems in humans. Long-term severe CR does not reduce the serum IGF-1 concentration or IGF-1:IGF-binding protein 3 ratio. In contrast, total and free IGF-1 concentrations are significantly lower in moderately protein-restricted individuals [91]. This evidence suggests that protein intake is a key determinant of circulating IGF-1 levels in humans. Reduced protein intake may therefore become an important component of anticancer and antiaging dietary interventions. Future studies are necessary to determine the mechanisms behind lifespan prolongation by CR in humans.

\section{Acknowledgment}

This work was supported in part by a grant from the Education Foundation of Zhejiang Province (Z200803827 to L.X.), China.

\section{References}

1 McCay CM, Crowell MF, Maynard LA: The effect of retarded growth upon the length of life span and upon the ultimate body size. J Nutr 1935;10:63-79.

2 Anderson RM, Weindruch R: Metabolic reprogramming, caloric restriction and aging. Trends Endocrinol Metab 2010;21:134-141.

3 Kennedy BK, Steffen KK, Kaeberlein M: Ruminations on dietary restriction and aging. Cell Mol Life Sci 2007;64:1323-1328.
4 Wood JG, Rogina B, Lavu S, Howitz K, Helfand SL, Sinclair D, Tatar M: Sirtuin activators mimic caloric restriction and delay ageing in metazoans. Nature 2004;430:686-689.

5 Masoro EJ: Caloric restriction and aging: an update. Exp Gerontol 2000;35:299-305.

6 Holliday R: Food, reproduction and longevity: is the extended lifespan of calorie-restricted animals an evolutionary adaptation? Bioessays 1989;10:125-127.
7 Nelson JF: Neuroendocrine involvement in the retardation of aging by dietary restriction: a hypothesis; in Yu BP (ed): Modulation of Aging Processes by Dietary Restriction. Boca Raton, CRC, 1994, pp 37-55.

8 Ahima RS, Prabakaran D, Mantzoros C, Qu D, Lowell B, Maratos-Flier E, Flier JS: Role of leptin in the neuroendocrine response to fasting. Nature 1996;382:250-252. 
9 Overton JM, Williams TD, Chambers JB, Rashotte ME: Central leptin infusion attenuates the cardiovascular and metabolic effects of fasting in rats. Hypertension 2001;37:663669.

10 Salway JG: Metabolism at a Glance. Oxford, Blackwell Science, 1999.

11 Hashimoto T, Cook WS, Qi C, Yeldandi AV, Reddy JK, Rao MS: Defect in peroxisome proliferator-activated receptor- $\alpha$-inducible fatty acid oxidation determines the severity of hepatic steatosis in response to fasting. J Biol Chem 2000;275:28918-28928.

12 Kersten S, Seydoux J, Peters JM, Gonzalez FJ, Desvergne B, Wahli W: Peroxisome proliferator-activated receptor- $\alpha$ mediates the adaptive response to fasting. J Clin Invest 1999; 103:1489-1498.

13 McCarter RJ, Palmer J: Energy metabolism and aging: a lifelong study of Fischer 344 rats. Am J Physiol 1992;263(pt 1):E448E452.

14 Higami Y, Pugh TD, Page GP, Allison DB, Prolla TA, Weindruch R: Adipose tissue energy metabolism: altered gene expression profile of mice subjected to long-term caloric restriction. FASEB J 2004;18:415-417.

15 Lauzurica N, García-García L, Pinto S, Fuentes JA, Delgado M: Changes in NPY and POMC, but not serotonin transporter, following a restricted feeding/repletion protocol in rats. Brain Res 2010;1313:103-112.

16 Shimokawa T, Kumar MV, Lane MD: Effect of a fatty acid synthase inhibitor on food intake and expression of hypothalamic neuropeptides. Proc Natl Acad Sci USA 2002;99: 66-71.

17 Xu B, Kalra PS, Farmerie WG, Kalra SP: Daily changes in hypothalamic gene expression of neuropeptide Y, galanin, proopiomelanocortin, and adipocyte leptin gene expression and secretion: effects of food restriction. Endocrinology 1999;140:2868-2875.

18 Sonntag WE, Xu X, Ingram RL, D'Costa A: Moderate caloric restriction alters the subcellular distribution of somatostatin mRNA and increases growth hormone pulse amplitude in aged animals. Neuroendocrinology 1995;61:601-608

19 Shimokawa I, Higami Y: A role for leptin in the anti-aging action of dietary restriction: a hypothesis. Aging (Milano) 1999;11:380382.

20 Breese CR, Ingram RL, Sonntag WE: Influence of age and long-term dietary restriction on plasma insulin-like growth factor-1 (IGF1), IGF-1 gene expression, and IGF-1 binding proteins. J Gerontol 1991;46:B180-B187.

21 Bronson FH: Food-restricted, prepubertal, female rats: rapid recovery of luteinizing hormone pulsing with excess food, and full recovery of pubertal development with gonadotropin-releasing hormone. Endocrinology 1986;118:2483-2487.
22 Hamilton GD, Bronson FH: Food restriction and reproductive development: male and female mice and male rats. Am J Physiol 1986; 250:R370-R376.

23 Sirotkin AV, Chrenkova M, Nitrayova S, Patras P, Darlak K, Valenzuela F, Pinilla L, Tena-Sempere M: Effects of chronic food restriction and treatments with leptin or ghrelin on different reproductive parameters of male rats. Peptides 2008;29:1362-1368.

24 Campbell GA, Kurcz M, Marshall S, Meites $\mathrm{J}$ : Effects of starvation in rats on serum levels of follicle stimulating hormone, luteinizing hormone, thyrotropin, growth hormone and prolactin: response to LH-releasing hormone and thyrotropin-releasing hormone. Endocrinology 1977;100:580-587.

25 Grizard G, Artonne C, Grizard J, Boucher D: Effect of short-term starvation on Leydig cell function in adult rats. Arch Androl 1997;38: 207-214

26 Sabatino F, Masoro EJ, McMahan CA, Kuhn RW: Assessment of the role of the glucocorticoid system in aging processes and in the action of food restriction. J Gerontol 1991; 46:B171-B179.

27 Masoro EJ, Compton C, Yu BP, Bertrand $\mathrm{H}$ Temporal and compositional dietary restrictions modulate age-related changes in serum lipids. J Nutr 1983;113:880-892.

28 Yamaza H, Komatsu T, Chiba T, Toyama H, To K, Higami Y, Shimokawa I: A transgenic dwarf rat model as a tool for the study of calorie restriction and aging. Exp Gerontol 2004;39:269-272.

29 McCarter RJ, McGee JR: Transient reduction of metabolic rate by food restriction. Am J Physiol 1989;257:E175-E179.

30 McCarter RJ, Palmer J: Energy metabolism and aging: a lifelong study of Fischer 344 rats. Am J Physiol 1992;263(pt 1):E448E452.

31 Koizumi A, Wada Y, Tuskada M, Kayo T, Naruse $\mathrm{M}$, Horiuchi $\mathrm{K}$, Mogi T, Yoshioka $\mathrm{M}$, Sasaki M, Miyamaura Y, Abe T, Ohtomo K, Walford RL: A tumor preventive effect of dietary restriction is antagonized by a high housing temperature through deprivation of torpor. Mech Ageing Dev 1996;92:67-82.

32 Ingram DK, Zhu M, Mamczarz J, Zou S, Lane MA, Roth GS, deCabo R: Calorie restriction mimetics: an emerging research field. Aging Cell 2006;5:97-108.

33 Roth GS, Lane MA, Ingram DK, Mattison JA, Elahi D, Tobin JD, Muller D, Metter EJ: Biomarkers of caloric restriction may predict longevity in humans. Science 2002;297:811.

34 Barzilai N, Banerjee S, Hawkins M, Chen W, Rossetti L: Caloric restriction reverses hepatic insulin resistance in aging rats by decreasing visceral fat. J Clin Invest 1998; 101 : 1353-1361.

35 Schwartz MW, Woods SC, Porte D Jr, Seeley RJ, Baskin DG: Central nervous system control of food intake. Nature 2000;404:661671.
36 Kadowaki T, Hara K, Yamauchi T, Terauchi Y, Tobe K, Nagai R: Molecular mechanism of insulin resistance and obesity. Exp Biol Med (Maywood) 2003;228:1111-1117.

37 Fruebis J, Tsao TS, Javorschi S, Ebbets-Reed D, Erickson MR, Yen FT, Bihain BE, Lodish HF: Proteolytic cleavage product of $30-\mathrm{kDa}$ adipocyte complement-related protein increases fatty acid oxidation in muscle and causes weight loss in mice. Proc Natl Acad Sci USA 2001;98:2005-2010.

38 Yamauchi T, Kamon J, Waki H, Terauchi Y, Kubota N, Hara, K, Mori Y, Ide T, Murakami K, Tsuboyama-Kasaoka N, Ezaki O, Akanuma Y, Gavrilova O, Vinson C, Reitman ML, Kagechika H, Shudo K, Yoda M, Nakano Y, Tobe K, Nagai R, Kimura S, Tomita M, Froguel P, Kadowaki T: The fat-derived hormone adiponectin reverses insulin resistance associated with both lipoatrophy and obesity. Nat Med 2001;7:941-946.

39 Yamauchi T, Kamon K, Minokoshi Y, Ito Y, Waki H, Uchida S, Yamashita S, Noda M, Kita S, Ueki K, Eto K, Akanuma Y, Froguel P, Foufelle F, Ferre P, Carling D, Kimura S, Nagai R, Kahn BB, Kadowaki T: Adiponectin stimulates glucose utilization and fatty-acid oxidation by activating AMP-activated protein kinase. Nat Med 2002;8:1288-1295.

40 Zhu M, Miura J, Lu LX, Bernier M, DeCabo R, Lane MA, Roth GS, Ingram DK: Circulating adiponectin levels increase in rats on caloric restriction: the potential for insulin sensitization. Exp Gerontol 2004;39:10491059.

41 Chitturi S, Abeygunasekera S, Farrell GC, Holmes-Walker J, Hui JM, Fung C, Karim R, Lin R, Samarasinghe D, Liddle C, Weltman $\mathrm{M}$, George J: NASH and insulin resistance: insulin hypersecretion and specific association with the insulin resistance syndrome. Hepatology 2002;35:373-379.

42 Unger RH, Orci L: Lipoapoptosis: its mechanism and its diseases. Biochem Biophys Acta 2002;1585:202-212.

43 Kristal BS, Yu BP: An emerging hypothesis: synergistic induction of aging by free radicals and Maillard reactions. J Gerontol 1992; 47:B107-B114.

44 Czaja MJ: Liver injury in the setting of steatosis: crosstalk between adipokine and cytokine. Hepatology 2004;40:19-22.

45 Chung HY, Kim HJ, Kim KW, Choi JS, Yu BP: Molecular inflammation hypothesis of aging based on the anti-aging mechanism of calorie restriction. Microsc Res Tech 2002; 59:264-272.

46 Shimokawa I, Higami Y: Leptin signaling and aging: insight from caloric restriction. Mech Ageing Dev 2001;122:1511-1519.

47 Rao MS, Reddy JK: Peroxisomal $\beta$-oxidation and steatohepatitis. Semin Liver Dis 2001;21: 43-55. 
48 Lemberger T, Saladin R, Vázquez M, Assimacopoulos F, Staels B, Desvergne B, Wahli $\mathrm{W}$, Auwerx J: Expression of the peroxisome proliferator-activated receptor- $\alpha$ gene is stimulated by stress and follows a diurnal rhythm. J Biol Chem 1996;271:1764-1769.

49 Janorkar AV, King KR, Megeed Z, Yarmush ML: Development of an in vitro cell culture model of hepatic steatosis using hepatocytederived reporter cells. Biotechnol Bioeng 2009;105:1466-1474.

50 Longo VD, Finch CE: Evolutionary medicine: from dwarf model systems to healthy centenarians? Science 2003;299:1342-1346.

51 Shimokawa I: Rodent models for the study of the role of growth hormone-insulin-like growth factor-1 or the insulin axis in aging and longevity: special reference to a transgenic dwarf rat strain and calorie restriction; in Nyberg FJ (ed): The Somatotrophic Axis in Brain Function. Burlington, Elsevier Academic, 2006, pp 173-184.

52 Kahn BB, Alquier T, Carling D, Hardie DG: AMP-activated protein kinase: ancient energy gauge provides clues to modern understanding of metabolism. Cell Metab 2005; 1 : 15-25.

53 Pallottini V, Montanari L, Cavallini G, Bergamini E, Gori Z, Trentalance A: Mechanisms underlying the impaired regulation of 3-hydroxy-3-methylglutaryl coenzyme A reductase in aged rat liver. Mech Ageing Dev 2004;125:633-639.

54 Brunet A, Bonni A, Zigmond MJ, Lin MZ, Juo P, Hu LS, Anderson MJ, Arden KC, Blenis J, Greenberg ME: Akt promotes cell survival by phosphorylating and inhibiting a forkhead transcription factor. Cell 1999;96: 857-868.

55 Kops GJ, de Ruiter ND, de Vries-Smits AM, Powell DR, Bos JL, Burgering BM: Direct control of the Forkhead transcription factor AFX by protein kinase B. Nature 1999;398: 630-634.

56 Ogg S, Paradis S, Gottlieb S, Patterson GI, Lee L, Tissenbaum HA, Ruvkun G: The Fork head transcription factor DAF-16 transduces insulin-like metabolic and longevity signals in C. elegans. Nature 1997;389:994-999.

57 Cheung PCF, Salt IP, Davies SP, Hardie DG, Carling D: Characterization of AMP-activated protein kinase $\gamma$-subunit isoforms and their role in AMP binding. Biochem J 2000; 346:659-669.

58 Guarente L, Kenyon C: Genetic pathways that regulate ageing in model organisms. Nature 2000;408:255-262.

59 Imai S, Armstrong CM, Kaeberlein M, Guarente L: Transcriptional silencing and longevity protein Sir2 is an NAD-dependent histone deacetylase. Nature 2000;403:795-800.

60 Brachmann CB, Sherman JM, Devine SE, Cameron EE, Pillus L, Boeke JD: The Sir2 gene family, conserved from bacteria to humans, functions in silencing, cell-cycle progression, and chromosome stability. Genes Dev 1995;9:2888-2902.
61 Afshar G, Murnane JP: Characterization of a human gene with sequence homology to $\mathrm{Sac}$ charomyces cerevisiae SIR2. Gene 1999;234: 162-166.

62 Gottlieb S, Esposito RE: A new role for a yeast transcriptional silencer gene, Sir2, in regulation of recombination in ribosomal DNA. Cell 1989;56:771-776.

63 Shore D, Squire M, Nasmyth KA: Characterization of 2 genes required for the positioneffect control of yeast mating-type genes. EMBO J 1984;3:2817-2823.

64 Kaeberlein M, McVey M, Guarente L: The SIR2/3/4 complex and SIR2 alone promote longevity in Saccharomyces cerevisiae by two different mechanisms. Genes Dev 1999;13: 2570-2580.

65 Tissenbaum HA, Guarente L: Increased dosage of a sir-2 gene extends lifespan in Caenorhabditis elegans. Nature 2001;410:227230.

66 Wang Y, Oh SW, Deplancke B, Luo J, Walhout AJM, Tissenbaum HA: C. elegans 14-33 proteins regulate life span and interact with SIR-2.1 and DAF-16/FOXO. Mech Ageing Dev 2006;127:741-747.

67 Rogina B, Helfand SL: Sir2 mediates longevity in the fly through a pathway related to calorie restriction. Proc Natl Acad Sci USA 2004;101:15998-16003.

68 Guarente L: Sirtuins as potential targets for metabolic syndrome. Nature 2006;444:868874.

69 Wullschleger S, Loewith R, Hall MN: TOR signaling in growth and metabolism. Cell 2006;127:5-9.

70 Inoki K, Guan KL: Complexity of the TOR signaling network. Trends Cell Biol 2006;16: 206-212.

71 Sarbassov DD, Ali SM, Sabatini DM: Growing roles for the mTOR pathway. Curr Opin Cell Biol 2005; 17:596-603.

72 Powers RW, Kaeberlein M, Caldwell SD, Kennedy BK, Fields S: Extension of chronological life span in yeast by decreased TOR pathway signaling. Genes Dev 2006;20:174184.

73 Min KJ, Tatar M: Restriction of amino acids extends lifespan in Drosophila melanogaster. Mech Ageing Dev 2006;127:643-646.

74 Miller RA, Buehner G, Chang Y, Harper JM, Sigler R, Smith-Wheelock M: Methioninedeficient diet extends mouse lifespan, slows immune and lens aging, alters glucose, T4, IGF-I and insulin levels, and increases hepatocyte MIF levels and stress resistance. Aging Cell 2005;4:119-125.

75 Zimmerman JA, Malloy V, Krajcik R, Orentreich N: Nutritional control of aging. Exp Gerontol 2003:38:47-52.

76 Kahn BB, Alquier T, Carling D, Hardie DG: AMP-activated protein kinase: ancient energy gauge provides clues to modern understanding of metabolism. Cell Metab 2005;1: $15-25$.
77 Inoki K, Guan KL: Complexity of the TOR signaling network. Trends Cell Biol 2006;16: 206-212.

78 Shaw RJ, Bardeesy N, Manning BD, Lopez L, Kasmatka M, DePinho RA, Cantley LC: The LKB1 tumor suppressor negatively regulates mTOR signaling. Cancer Cell 2004;6:91-99.

79 Bishop NA, Guarente L: Two neurons mediate diet-restriction-induced longevity in $C$. elegans. Nature 2007;447:545-549.

80 Panowski SH, Wolff S, Aguilaniu H, Durieux J, Dillin A: PHA-4/Foxa mediates dietrestriction-induced longevity of C. elegans. Nature 2007;447:550-555.

81 Mango SE, Lambie EJ, Kimble J: The pha-4 gene is required to generate the pharyngeal primordium of Caenorhabditis elegans. Development 1994;120:3019-3031.

82 Kenyon C, Chang J, Gensch E, Rudner A, Tabtiang RA: A C. elegans mutant that lives twice as long as wild type. Nature 1993;366: 461-464.

83 Brenkman AB, Burgering BMT: Live longer through PHAsting. Cell Metab 2007;5:407409 .

84 Wolfrum C, Asilmaz E, Luca E, Friedman JM, Stoffel M: Foxa2 regulates lipid metabolism and ketogenesis in the liver during fasting and in diabetes. Nature 2004;432:10271032.

85 Walker AK, See R, Batchelder C, Kophengnavong T, Gronniger JT, Shi Y, Blackwell TK: A conserved transcription motif suggesting functional parallels between Caenorhabditis elegans SKN-1 and Cap'n'Collar-related basic leucine zipper proteins. J Biol Chem 2000; 275:22166-22171

86 Hayes JD, McMahon M: Molecular basis for the contribution of the antioxidant responsive element to cancer chemoprevention. Cancer Lett 2001;174:103-113.

87 Wolf CR: Chemoprevention: increased potential to bear fruit. Proc Natl Acad Sci USA 2001;98:2941-2943.

88 Bowerman B, Eaton BA, Priess JR: Skn-1, a maternally expressed gene required to specify the fate of ventral blastomeres in the early C. elegans embryo. Cell 1992;68:10611075 .

89 Everitt AV, le Couteur DG: Life extension by calorie restriction in humans. Ann NY Acad Sci 2007; 1114:428-433.

90 Ingram DK, Roth GS, Lane MA, Ottinger MA, Zou S, Cabo R, Mattison JA: The potential for dietary restriction to increase longevity in humans: extrapolation from monkey studies. Biogerontology 2006;7:143-148.

91 Fontana L, Weiss EP, Villareal DT, Klein S, Holloszy JO: Long-term effects of calorie or protein restriction on serum IGF-1 and IGFBP-3 concentration in humans. Aging Cell 2008;7:681-687. 